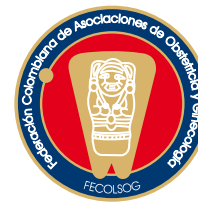

Editorial

\title{
LOS CONGRESOS EN CARTAGENA: UNA POSIBILIDAD DE RETORNO SOCIAL
}

\section{Congresses in Cartagena: a possibility of social return}

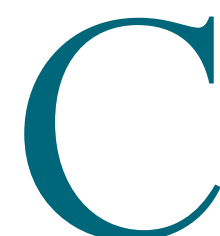

ada vez que se prepara un Congreso de Obstetricia y Ginecología, Perinatología, Medicina Materno Fetal u otra área especializada de la medicina en la ciudad de Cartagena, se refuerzan los lazos gremiales, se invitan expertos mundiales para divulgar las nuevas evidencias y se proyecta una positiva imagen de nuestro país y de su gente. Con satisfacción y luego de agotadoras jornadas, los presidentes de estos exitosos proyectos presentan a sus colegas el número total de asistentes, los premios a las mejores investigaciones, los comentarios de los invitados extranjeros sobre nuestro nivel científico y las "utilidades" en términos de educación continuada, ventas y aportes de las multinacionales farmacéuticas.

Sin embargo, paralelo a los cuatro días de posters, muestras de tecnología médica avanzada, presentaciones orales y conferencias magistrales, un importante número de mujeres en esta ciudad, como en otras ciudades de Colombia , mujeres sin empleo ni seguridad social, con escasa educación enfrentan nuevos problemas de salud, tales como: embarazos no deseados o nuevos casos de cáncer de mama o de cérvix.

Cartagena, centro nacional de divulgación de nuevas evidencias y lugar de encuentros de sociedades científicas, es también una ciudad de grandes inequidades en Colombia, donde la pobreza y las dificultades para acceso a los servicios de salud se conjugan para tener una alta tasa de mortalidad materna y perinatal, para que la incidencia de VIH y otras infecciones de transmisión sexual (ITS) se consideren problemas de Salud Sexual y Reproductiva y donde el embarazo en adolescentes por su alta prevalencia refuerza el círculo de la pobreza.

Pero en el contexto de estos congresos, se puede hacer mucho por las mujeres de Cartagena. En esta como en otras ciudades de Colombia, los casi 2.500 ginecólogos que asisten sin falta a estos encuentros tienen muchísimo que ofrecer. Sus conocimientos, habilidades y talentos son un privilegio social que junto con algún esfuerzo logístico, económico y sentido de corresponsabilidad se traducirían en atención oportuna y con calidad a muchas mujeres pobres de la ciudad anfitriona.

Realizar jornadas masivas para tamización del cáncer de mama, colposcopias para patología cervical o atención prioritaria a mujeres de alto riesgo obstétrico y perinatal en el contexto de un Congreso Nacional de Ginecología se convierte en una excelente oportunidad para que el gremio médico reivindique su vocación de servicio, y el desarrollo de políticas públicas hacia este grupo humano que luego retornará con creces este pequeño esfuerzo. No solucionará las pobrezas o dificultades de las mujeres pobres de las ciudades donde hacemos estos eventos, pero si brinda una oportunidad de que la gente más pobre reciba parte de los beneficios de la visita de tan ilustres visitantes.

Alejandro Vargas, M.D., MSc Hernando Gaitán Duarte, M.D., MSc

Editor 